\title{
Unconventional use of the Fogarty embolization catheter for retrieval of a disjointed endovascular ventricular assist device
}

Yann Beaulieu, B Eng, ${ }^{\mathrm{a}}$ Nicola Vistarini, MD, MSc, ${ }^{\mathrm{a}, \mathrm{b}}$ Yoan Lamarche, MD, MSc, ${ }^{\mathrm{a}}$ and Louis P. Perrault, MD, PhD, ${ }^{\mathrm{a}}$ Montreal, Canada, and Pavia, Italy

See related commentary on pages e43-4.

A 68-year-old man was admitted with acute coronary syndrome after acute myocardial infarction with cardiorespiratory arrest and ventricular arrhythmic storm. A double primary angioplasty was performed, and an intra-aortic balloon pump was inserted. Iliofemoral angiography showed no stenosis, narrowing, or tortuosity of the arteries. Despite the interventions and the high doses of vasopressors and inotropes, the arrhythmia persisted and the patient experienced progressive cardiogenic shock. For these reasons, an Impella 5.0 (Abiomed Inc, Danvers,

From the ${ }^{\mathrm{a}}$ Department of Cardiac Surgery, Montreal Heart Institute, Université de Montréal, Montreal, Canada; and bepartment of Clinical-Surgical, Diagnostic and Pediatric Sciences, Pavia University School of Medicine, Pavia, Italy.

Disclosures: Authors have nothing to disclose with regard to commercial support.

Received for publication Feb 11, 2015; revisions received April 30, 2015; accepted for publication May 18, 2015; available ahead of print June 12, 2015.

Address for reprints: Louis P. Perrault, MD, PhD, Department of Cardiac Surgery,

Montreal Heart Institute, Université de Montréal, 5000 Bélanger St, Montreal,

Quebec, H1T 1C8 Canada (E-mail: louis.perrault@icm-mhi.org).

J Thorac Cardiovasc Surg 2015;150:e41-3

$0022-5223 / \$ 36.00$

Copyright (c) 2015 by The American Association for Thoracic Surgery

http://dx.doi.org/10.1016/j.jtcvs.2015.05.040
Mass) device was implanted via the left common femoral artery through a $10-\mathrm{mm}$ Dacron graft. The femoral artery appeared normal at intraoperative evaluation. However, the surgical access was difficult (intraoperative bleeding, $1025 \mathrm{~mL}$ ) because the patient was obese and the angle of the anastomosis of the Dacron graft was very steep. Four days after the operation, the patient was progressively weaned from the Impella device. Because the device was being manipulated for withdrawal, a moderate resistance was perceived that required additional traction force. After "milking" the device through the Dacron anastomosis, the Impella device was finally withdrawn without forceful tugging; however, the distal part of the device was missing! The Impella device had disjointed at the interface between the motor pump and the Hydex ring (Figure 1, A). The elected emergency strategy was to use a Fogarty arterial embolectomy catheter (Edwards Lifesciences, Irvine, Calif) to pull and recover the remaining intra-arterial segment under fluoroscopy. Because the distal part of the Fogarty catheter was adjacent to the cannula (Figure 1, $B$ ) but could not surpass the pigtail of the Impella device, an unconventional technique was tried: The 9-mm balloon was progressively inflated with contrast agent adjacent to the distal end of the Impella cannula. Sufficient lateral pressure was thus applied between the Fogarty balloon and the Impella part

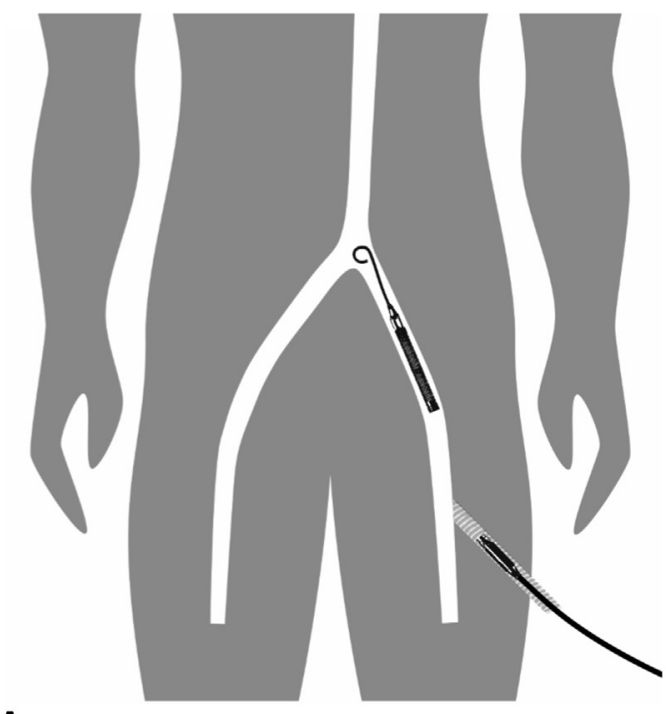

A

FIGURE 1. A, Decoupling of the Impella 5.0 device (Abiomed Inc, Danvers, Mass) at the iliac level on its excision. B, Emergency retrieval procedure of the missing intra-arterial segment of the Impella with a 4F Fogarty balloon catheter (Edwards Lifesciences, Irvine, Calif). C, Representation of an intact Impella 5.0 device ( $I$, 9F driveline catheter; $I I, 21 \mathrm{~F}$ pump motor; $I I I, 21 \mathrm{~F}$ cannula; $I V$, pigtail). 

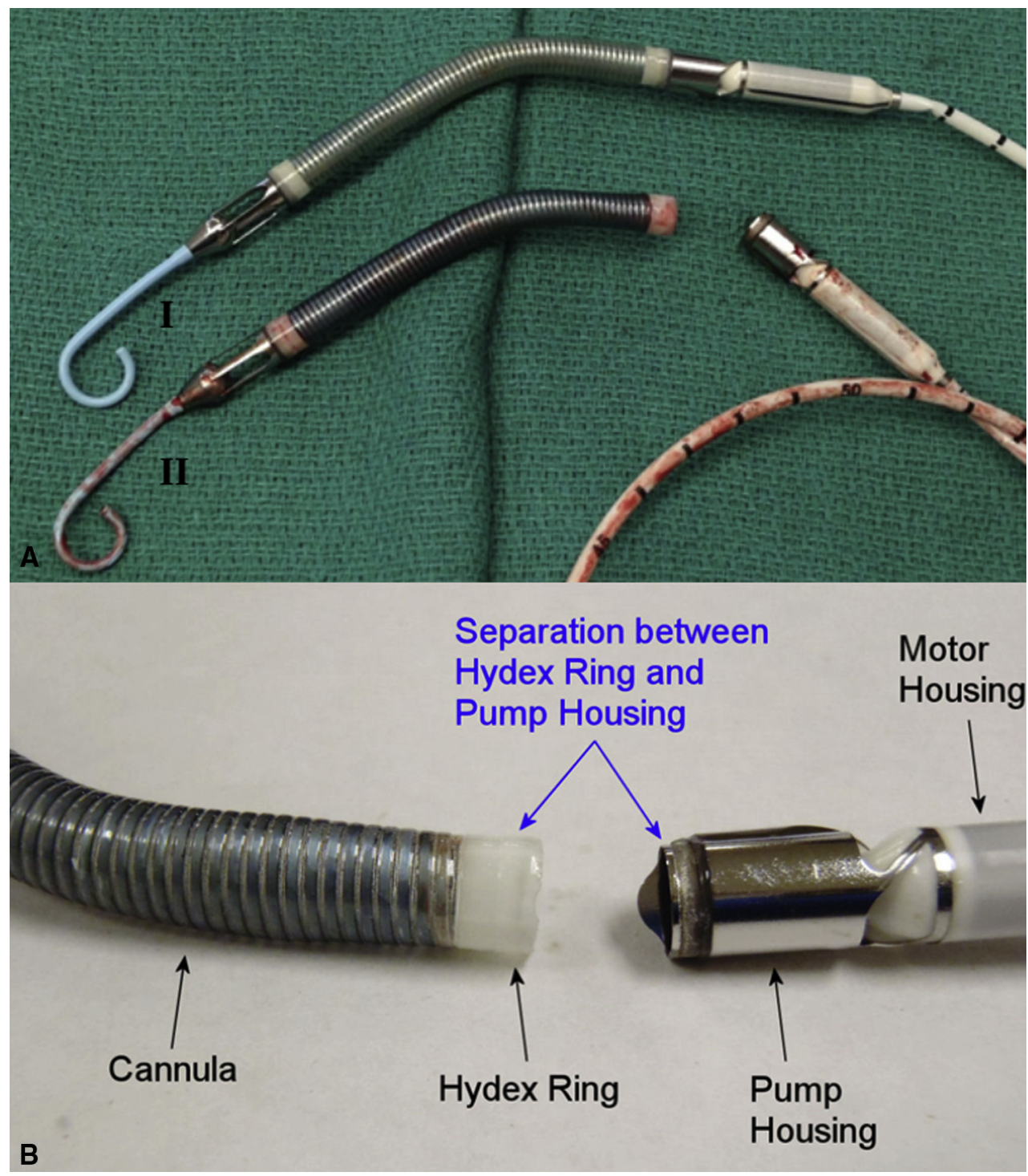

FIGURE 2. A, Comparison of a new Impella 5.0 (I) device with the disjointed Impella device after retrieval (II). B, Hydex ring and pump housing interface of the disjointed Impella.

to frictionally connect the elements and withdraw the Impella and the balloon as a unit (Figure 1, B). By steadily retrieving the Fogarty probe, the remaining pump segment was successfully and uneventfully withdrawn. The patient was discharged in stable condition 18 days after the procedure because he experienced transient right ventricular dysfunction, acute renal failure, and pleural effusions. The lower limb did not experience any complications, the flow through the artery at the end of the operation was excellent, the peripheral oximetry was normal, and the patient had no embolic injury to the feet or toes.

\section{DISCUSSION}

The safety and efficacy of the Impella device have been proven in many publications. ${ }^{1,2}$ Complications related to the use of these devices have been described, ${ }^{2-5}$ but they have never been reported in a case similar to ours. After examination of the returned defective Impella device, Abiomed's quality team suggested that a possible explanation could be that deformation of the metal pump housing during insertion weakened the connection at the Hydex ring and pump interface (Figure 2). The combination of this already weak bond and unusual bending/tensile stresses on the mobilization of the device led to the decoupling and "loss" of the cannula-pigtail segment. However, the insertion of the device was accomplished according to the manufacturer's recommendations and was uneventful in 19 cases before this one. For successful Impella implantation we recommend the following: (1) insertion and withdrawal in the hybrid suite with use of fluoroscopy; (2) avoidance of use of sharp instruments when handling the device; and (3) use of an alternate cannulation route in case 
of arterial deformity, atherosclerosis, or calcification, with liberal use of side grafts to artery.

Limited options were available to manage the intra-arterial decoupling of the Impella device. Because time was of the essence, we performed an emergency retrieval of the Impella pump segment in the operating room, where the setup and equipment for endovascular image-guided interventions are not optimal compared with a catheterization laboratory. Accordingly, a portable fluoroscopy $\mathrm{C}$-arm x-ray machine was used to identify the device segment and "manually" follow the intervention. Surgical removal would have been the last resort considering the already precarious medical condition of the patient. Other conventional nonoperative alternatives for this endovascular foreign body retrieval consist of using snare catheters or graspers in a standard fluoroscopic/ radiographic room. The key to safety for this type of procedure is fluoroguidance and transesophageal echocardiography monitoring, which were both available in our case.

\section{CONCLUSIONS}

We report a case of an intra-arterial disjointed Impella device, a rare complication that was successfully managed with an unconventional use of the Fogarty embolization catheter. To prevent such a complication, it is advisable to schedule pump withdrawal in the hybrid operating room and, in case of unusual resistance, to avoid excessive force during retrieval, using the fluoroscopy to guide device withdrawal.

\section{References}

1. Lamarche Y, Cheung A, Ignaszewski A, Higgins J, Kaan A, Griesdale DE, et al Comparative outcomes in cardiogenic shock patients managed with Impella microaxial pump or extracorporeal life support. J Thorac Cardiovasc Surg. 2011:142:60-5.

2. Griffith BP, Anderson MB, Samuels LE, Pae WE Jr, Naka Y, Frazier OH The RECOVER I: a multicenter prospective study of Impella 5.0/LD for postcardiotomy circulatory support. J Thorac Cardiovasc Surg. 2013;145: 548-54.

3. Bhat TM, Waked A, Teli S, Lafferty J, Gala B. Acute complication due to Impella 2.5 device (superficial femoral artery thrombosis): managed successfully with novel aspiration thrombectomy catheter (pronto v3). Clin Med Insights Cardiol. 2011;5:17-21.

4. Meyns B, Dens J, Sergeant P, Herijgers P, Daenen W, Flameng W Initial experiences with the Impella device in patients with cardiogenic shock - Impella support for cardiogenic shock. Thorac Cardiovasc Surg. 2003;51:312-7.

5. Dixon SR, Henriques JP, Mauri L, Sjauw K, Civitello A, Kar B, et al. A prospective feasibility trial investigating the use of the Impella 2.5 system in patients undergoing high-risk percutaneous coronary intervention (The PROTECT I Trial): initial U.S. experience. JACC Cardiovasc Interv. 2009; 2:91-6.

\section{EDITORIAL COMMENTARY}

\section{Are devices for temporary mechanical circulatory support getting safer?}

Jonathan W. Haft, MD

See related article on pages e41-3.

I read with interest the case report from Beaulieu and colleagues, ${ }^{1}$ in which an Impella 5.0 microaxial blood pump (Abiomed, Danvers, Mass) fractured during withdrawal after 4 days of use following an acute myocardial infarction.

\footnotetext{
From the Department of Cardiac Surgery, University of Michigan, Ann Arbor, Mich. Disclosures: Author has nothing to disclose with regard to commercial support.

Received for publication May 28, 2015; accepted for publication June 3, 2015; available ahead of print July 2, 2015.

Address for reprints: Jonathan W. Haft, MD, Department of Cardiac Surgery, University of Michigan, 1500 E Medical Center Dr, Ann Arbor, MI 48109 (E-mail: haft@umich.edu).

J Thorac Cardiovasc Surg 2015;150:e43-4 $0022-5223 / \$ 36.00$

Copyright (c) 2015 by The American Association for Thoracic Surgery http://dx.doi.org/10.1016/j.jtcvs.2015.06.012
}

They were able to expeditiously and creatively retrieve the dislodged fragment from the aortic bifurcation without additional invasive approaches and without harm to the patient. The authors should be congratulated on their outcome, and specifically, on the successful use of temporary me-

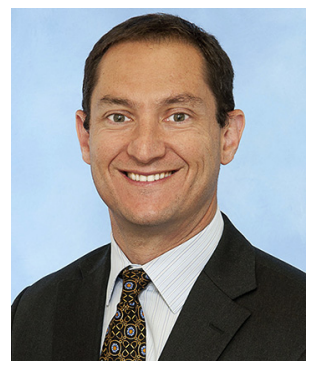
chanical circulatory support for cardiogenic shock. Their strategy to initiate support early prevented end-organ injury and the inevitable decline from multisystem organ failure that is so often seen in protracted low-cardiac output states.

Temporary mechanical circulatory support encompasses a spectrum of devices that includes peripheral and centrally employed extracorporeal blood pumps, extracorporeal 